\title{
UM ESTUDO SOBRE IDOSOS ASILADOS COM CEGUEIRA ADQUIRIDA
}

\author{
Rosimara Cargnin ${ }^{*}$ \\ Marco Aurélio Acosta*
}

\section{Resumo}

Este trabalho foi desenvolvido com o objetivo de conhecer melhor a vida de idosas asiladas do Asilo Amparo Providencia Lar das Vovozinhas, com cegueira adquirida; sua autonomia diária e as estratégias de enfrentamento das mesmas frente a aquisição de tal deficiência. Os sujeitos da pesquisa são cinco idosas internas na instituição acima referida. Como forma de coleta de dados foram realizadas entrevistas, que podem ser caracterizadas como de história oral, onde se procurou reunir informações da vida das colaboradoras através de um roteiro com questões abertas aplicado as mesmas e, outro roteiro com questões abertas aplicado a pessoas que atualmente fazem parte do meio em que as colaboradoras estão inseridas, como forma de obter informações sobre a autonomia de cada idosa que faz parte do estudo e após, foi realizada análise qualitativa. Foram observadas para o estudo as conseqüências da institucionalização e da aquisição da cegueira, assim como um breve relato sobre o histórico da instituição e sua estrutura atual. Concluiu-se que quanto mais o aspecto social estiver desenvolvido maior é a possibilidade de autonomia nas atividades de vida diária.

Palavras-chave: Terceira Idade. Asilos. Cegos.

\section{Introdução}

O cotidiano do idoso vem sofrendo alterações, muitos mantém uma participação ativa na sociedade, exercendo sua cidadania, porém é perceptível o grande número de pessoas idosas que são excluídas e mui-

\footnotetext{
* Especialista em Ciência do Movimento Humano (UFSM). Professor do quadro do magistério do município de Pinhal Grande, área: Educação Especial. E-mail: rcargnin@yahoo.com.br

** Doutor em Ciência do Movimento Humano (UFSM).Professor Adjunto do Departamento de métodos e Técnicas Desportivas da Universidade Federal de Santa Maria. E-mail: marco.acosta@bol.com.br
} 
tas vezes abandonadas pelas próprias famílias em instituições de longa permanência, também conhecidas por asilos ou instituições asilares de abrigo.

Nas instituições asilares de Santa Maria, e principalmente no Asilo Amparo Providência Lar das Vovozinhas encontramos internos com algum tipo de problema psiquiátrico ou orgânico, como o caso da surdez, deficiência física e cegueira.

Este trabalho teve como objetivo verificar as diferentes estratégias de enfrentamento em idosos institucionalizados no Asilo Amparo Providência Lar das Vovozinhas frente à aquisição da cegueira, além de suas limitações e potencialidades quanto a sua autonomia diária.

Cinco idosas cegas do asilo Amparo Providência Lar das Vovozinhas fizeram parte deste estudo, pois apesar de serem sete as cegas encontradas neste local, duas, (Cássia e Lúcia) não se enquadraram nas especificações dos sujeitos desta pesquisa, pois a primeira possui um prejuízo cognitivo, e a segunda é caracterizada como tendo cegueira congênita.

A estrutura física, o comportamento de alguns funcionários, a forma de identificação das salas encontradas nesta instituição de longa permanência não condizem com todas as limitações apresentadas por este público. A sociedade de uma forma geral está organizada para videntes, ouvintes e para pessoas que se locomovem com autonomia.

Esta desatenção ao mundo da cegueira neste tipo de instituição provavelmente origina-se na predominância da visão na maioria dos internos. Certas dificuldades se tornam então encobertas pela familiaridade, ocultas pelo hábito, linguagem e senso comum numa "cultura de videntes."

\section{Material e Métodos}

Este trabalho de pesquisa baseou-se na história oral, foi complementada com registros fotográficos, entrevista, observações, análise documental e diário de campo que serviram para clarear o mesmo.

Primeiramente buscaram-se informações junto ao Asilo Amparo Providência Lar das Vovozinhas na secretaria sobre a residência e o número de indivíduos com cegueira adquirida na instituição e em plenas condições mentais. Após, foram realizados os primeiros contatos com 
estes sujeitos, a fim de se criar vínculos afetivos.

Construiu-se para a realização da pesquisa um roteiro com questões norteadoras organizadas em grandes blocos, com uma temática associada, aplicado às cinco idosas cegas do Asilo. Foi feito também, um roteiro com questões abertas realizado com as pessoas que fazem parte do circulo de amizade dos sujeitos da pesquisa, a fim de se fazer uma rede de informações sobre os indivíduos do estudo, objetivando buscar informações sobre o comportamento social e psicológico das internas na instituição com o auxilio das amigas.

Em contato com a secretaria do Asilo, foram buscadas informações sobre o cotidiano asilar em termos quantitativos e qualitativos, assim como informações históricas e organização física. No mesmo local, foram encontradas as fichas das internas, com algumas informações importantes, como datas. Estas fichas dos sujeitos da pesquisa foram posteriormente fotocopiadas.

Dentro dos procedimentos tomados para a realização deste estudo foram levadas em consideração as indicações da Resolução $\mathrm{n}^{\circ}$ 196/96, que estabelece as normas de pesquisa envolvendo seres humanos.

\section{Análise e Discussão dos Resultados}

Para compreendermos a realidade e o significado de um envelhecer para cada indivíduo, é necessário conhecermos o local onde este velho reside e sua representação em diferentes épocas e lugares, além de suas experiências, suas vivências acumuladas durante toda a sua existência terrena.

O Asilo Amparo Providência Lar das Vovozinhas foi fundado em 1946 por Constantino Cordioli. A partir de 2001, sob a coordenação das irmãs Filhas de Santa Maria da Providência, as vagas foram organizadas e limitadas, e para cada novato é organizada uma pasta com seus dados, porém muitas internas não possuem informações suficientes em seus registros por serem remanescentes da estrutura antiga, como o caso da não especificação do tipo de deficiência que o interno possui, quando for o caso. Esta ficha também não é atualizada quando, por exemplo, depois de um tempo de internamento o sujeito adquirir uma deficiência. 
O Asilo Amparo Providência Lar das Vovozinhas, segundo sua secretaria, conta com mais de 200 internos, destes, a grande maioria são do gênero feminino. Em contato com a secretária da instituição e levando em consideração os anos de trabalho ali realizados foi possível observar que do total de internos aproximadamente $90 \%$ possuem algum tipo de deficiência (visual, mental, auditiva, neurológica, física).

Os quartos dos internos estão dispostos em seis alas, cada ala possui um número correspondente como forma de organização. Antigamente estas alas possuíam o nome de uma entidade da Igreja Católica. A disposição das alas se dá por critérios diferentes, como autonomia física ou mental:

a) Ala 1: antiga Santa Rita, localizada na parte da frente do Asilo, onde ficam as pessoas que gostam mais de caminhar ao ar livre e possuem mais autonomia. Nesta ala moram três pessoas cegas, porém uma não fez parte deste estudo por ser considerada com cegueira congênita;

b) Ala 2: antiga Nossa Senhora Aparecida, é a enfermaria, onde ficam os internos que estão muito doentes ou em fase de recuperação hospitalar. Nesta ala são residentes duas cegas, porém apenas uma fez parte deste estudo, devido às poucas condições mentais da outra;

c) Ala 3: antiga Providência, por ser um espaço fechado, é neste local que a maioria dos internos com problemas psiquiátricos graves ou deficiência mental severa ficam;

d) Ala 4: antigo Sagrado Coração de Jesus, nesta ala deveriam ficar as pessoas que podem subir e descer escadas, porém muitas das que ali residem não conseguem nem caminhar sozinhas, ficando as vezes por muitos dias sem dar uma caminhada no pátio, como relata Cecília, (moradora desta ala e sujeito deste estudo): "Elas não me tiram daqui (sala), ficam tudo dentro de casa entocada, passaram o dia inteiro dentro de casa. Ninguém me tira para sair.";

e) Ala 5: antiga Rainha da Paz, atualmente esta ala está sendo desocupada por ser um lugar mais distante da parte central do Asilo, além de ser bastante úmida. Os quartos que já foram desocupados foram reformados e transformados em salas onde são desenvolvidos projetos de extensão e outros trabalhos voluntários com as institucionalizadas; 
f) Ala 6: antiga São José, onde ficam os homens. Em cada ala, além da irmã coordenadora há outros cuidadores, geralmente técnicos em enfermagem, com exceção das alas 6 e 5 que por possuírem poucos indivíduos, recebem supervisão um pouco de cada irmã.

Muitas internas auxiliam na limpeza, organização dos quartos e na cozinha. Estes trabalhos não são obrigatórios, mas estimulados, e pode-se observar que deixam as internas incentivadas por considerarem estas atividades laborais responsabilidades próprias. Com o auxilio nas atividades da rotina do Lar muitas internas sentem-se úteis, que sua contribuição é importante para o bom andamento do asilo, dessa forma dificilmente ou praticamente nunca, passam os dias na sala ou no quarto fechadas.

Ao chegarmos ao Asilo os gritos muitas vezes assustadores em um primeiro momento, logo são esquecidos com um sorriso largo e uma frase acolhedora que é repetida "Que bom que tu veio!", assim a imagem que antes nos deixava apreensivos agora nos alegra. Paramos e agora também ouvimos músicas, risos, pessoas conversando amigavelmente, é a rotina da vida no Asilo Amparo Providência Lar das Vovozinhas que segue seu rumo, com pessoas diferentes em sua raça, credo, costumes e história, mas com muitos sentimentos semelhantes.

Para conhecermos melhor cada uma das internas que fazem parte deste estudo, apresentaremos agora um pouco de sua história pessoal, dando ênfase à forma da aquisição da cegueira, para preservarmos suas identidades foram lhes designados nomes fictícios.

Olga (96 anos, no último cadastro do asilo 7 anos de internamento, segundo ela, está internada a 20 anos). Ficou cega com aproximadamente 30 anos, morava no interior e trabalhava na lavoura, um dia colocando veneno no fumo entrou agrotóxico em seus olhos. Devido à distância não procurou atendimento médico no mesmo dia. Mesmo depois de cega teve todo o apoio do marido nas atividades de vida diária, constituiu família, se adaptou aos serviços domésticos que passou a desempenhar com autonomia. Não deixou de freqüentar festas e outros tipos de atividades da vida social, e ainda hoje dança.

Tereza (71 anos, 18 anos de internamento). Ficou cega aos 50 anos, de Glaucoma, era professora, tinha uma vida independente, foi casada, se separou, perdeu o contato com os filhos. Apesar de ter inde- 
pendência nas atividades de vida diária (toma banho, se veste, faz combinação de peças de roupas, se desloca relativamente bem na sua ala...) não aceita a cegueira, dizendo que a cegueira foi muito negativa para a sua vida, sendo esta a causa de sua internação no asilo.

Antonia (86 anos, 40 anos de internamento) Ficou cega com 20 anos, não sabe com certeza a causa, mas acredita ter sido um derrame. Fez tratamento na cidade de Porto Alegre, durante o tratamento teve um filho e foi obrigada a dar o bebê, foi abandonada pelo marido devido à deficiência. Trabalhou como lavadeira, e empalhava cadeira depois de cega, foi para o asilo devido ao falecimento de seus pais. Na instituição foi coordenadora de uma das alas (dava remédio para as internas, limpava e organizava o ambiente interno e externo, passeava na cidade). Atualmente tem uma deficiência auditiva moderada, mas ainda anda pelo asilo sozinha. Às vezes passa alguns meses na casa de seus familiares, mas retorna para a instituição por vontade própria.

Lurdes (75 anos, 33 anos de internamento). Ficou cega depois de sua internação asilar, por causa do Diabetes. Antes da institucionalização trabalhava em um asilo, por este motivo não se importou com a internação, pois continuou desenvolvendo as mesmas atividades. A cegueira lhe tirou toda a independência, agora passa os dias sentada em um sofá, não conversa com ninguém, não se alimenta e nem faz a sua higiene sozinha, fechou-se para o mundo.

Cecília (74 anos, 4 anos de internamento). Não aceita a cegueira por isso algumas vezes se queixa da condição de cego dizendo ser um impedimento para a realização das atividades, outras vezes diz que ela não é cega, e acredita que vai recuperar a visão. Também não aceita a condição de asilada, dizendo que logo irá embora; que faz poucos dias que está no asilo; que sua patroa, por quem foi criada virá buscá-la. Não se locomove sozinha e nem realiza sua higiene, além de não se comunicar com quase ninguém na instituição.

O processo de internação representa ao idoso o desafio de adaptar-se ao novo, que nem sempre é agradável, principalmente por que este momento vem entrelaçado com sentimento de abandono e com medo de passar os últimos anos de sua vida neste lugar estranho, com indivíduos que lhe são desconhecidos. Muitas vezes, então, cria fantasias de que ficará apenas alguns dias, ou esta é a informação que lhe é dada quando da sua internação, por seus familiares, numa forma de ilu- 
dir-se, e quem sabe não sucumbir tão fortemente ao medo e ao desamparo. É o que percebemos na fala de Cecília quando lhe perguntamos a quanto tempo está internada: "[ . . . ] vim agora, amanhã ou depois já vou de volta, eu vim só consultar. Vim ver a minha perna, o meu pé, como é que tá os meus olhos [... ]."

Cortelletti, Casara e Herédia ( 2004, p.21), também comentam que: "As representações e os sentimentos que o idoso havia desenvolvido a respeito de si próprio, a partir do conjunto de vivências, são deixadas de lado, sendo o seu eu descaracterizado."

A entrada neste mundo implica a necessidade da criação de novos vínculos afetivos, porém a fragilidade do ser dificulta esta construção, dependendo da história pessoal, o indivíduo terá diferentes graus de disponibilidade para esta aceitação ou não.

Observemos o que Cardoso (2001, p.1) coloca neste trecho:

Quando vemos os asilados em seus corpos pesados, com dificuldades para movimentarem-se, quando os vemos com as bocas escancaradas sem dentes, vemos todos os miseráveis deste país. Remontamos a história de vida de muitos de nossos avós, tios, irmãos, que, devido a pobreza e a desinformação, agonizaram até a morte pelo misto da doença física e mental. Alguns destes também foram internos e presos, amarrados em quartos fechados para a manutenção de suas vidas. Que vida?

Quando lemos este parágrafo, no qual a autora está justamente falando dos asilados do Lar das Vovozinhas, onde este trabalho foi desenvolvido, talvez percebemos o quanto a institucionalização está presente nas nossas vidas, no passado ou no futuro. Paramos e percebemos que estas pessoas foram vítimas do destino e do sistema, assim como nós, possuidores de um presente que nos esconde o futuro. $\mathrm{O}$ internamento asilar, na maioria das vezes faz com que as pessoas tornem-se desleixadas com o próprio corpo, ou não dá condições de cuidados, "criando" assim a diminuição do amor próprio por condições estéticas. Cria também um império de medo, de controle, de vigilância, um aculturamento ao mundo da instituição, como diz Cardoso (2001) e Goffman (1996), falando da mortificação dos sujeitos e da cultura. Pessoas 
estas marcadas pela dor, onde o humano já embruteceu, e a sociedade agora os chama "loucos, dementes."

Apesar dos vários exemplos anteriormente citados serem bastante fortes e difíceis de aceitar, não podemos esquecer que muitas dessas condições são impostas apenas para o bom andamento da instituição. Goffman (1996,p.48) confirma este pensamento quando diz:

[ . . ] as várias justificativas para a mortificação do eu são muito freqüentemente simples racionalizações, criadas por esforços para controlar a vida diária de grande número de pessoas em espaço restrito e com pouco gasto de recursos. Além disso, as mutilações do eu ocorrem, mesmo quando o internado está cooperando e a direção tem interesses ideais pelo seu bem estar.

Educacionalmente, as pessoas com deficiência visual são divididas em dois grupos: cegos e portadores de visão subnormal. A classificação, segundo a Sociedade Brasileira de Visão Subnormal ([2003]) é feita a partir da acuidade visual. A cegueira também pode ser subdividida em cegueira total e parcial: a cegueira total pressupõe completa perda de visão, ou seja, nem a percepção luminosa está presente e em oftalmologia isso significa visão zero. A cegueira parcial é onde estão os indivíduos apenas capazes de contar dedos a pouca distância e os que só vêem vultos.

Uma pessoa com visão subnormal é aquela que possui um comprometimento de seu funcionamento visual, mesmo após tratamento e/ou correção de erros refracionais comuns e tem uma acuidade visual inferior a 20/60 $(6 / 18,0.3)$ de percepção de luz ou campo visual inferior a 10 graus do seu ponto de fixação, mas que utiliza ou é potencialmente capaz de utilizar a visão para planejamento e execução de uma tarefa . (SOCIEDADE ..., [2003]) $)^{1}$

Segundo Anache (1994) a cegueira pode ser congênita ou adquirida: as pessoas que nasceram cegas ou que assim se tornaram antes do cinco anos de idade, não possuem memória visual útil da cor, e são ${ }^{1}$ Documento eletrônico. 
consideradas com cegueira congênita. Neste caso há um "aprender" o cotidiano sem a utilização do sentido responsável pelo visual, o que faz com que a pessoa se adapte ao seu ambiente da melhor forma possível, sendo às vezes quase impossível para nós, ditos normais, compreender como o cego se locomove percebendo vibrações, cheiros e ruídos quase imperceptíveis para nós, que pela falta de necessidade não aguçamos estes sentidos.

Conforme Anache $(1994$, p.83)" $[$. . . ] os sujeitos que ficam cegos a partir dos cinco anos de idade são classificados como tendo cegueira adquirida, estes devem ter retido imagens visuais e a idéia da cor que utilizam no seu cotidiano." Estes geralmente apresentam maior dificuldade de adaptação no seu meio, pois já foram adaptados como videntes, sendo necessária uma readaptação. Estes mecanismos de busca utilizados pelo sujeito a fim de se sentir familiarizado novamente com seu entorno, podem acarretar mudanças de comportamento frente às várias situações. O que antes the era familiar deixa de ser a partir do momento em que não pode mais ser visto. $\mathrm{O}$ indivíduo tem que passar por um processo de assimilação e acomodação das atividades que realizava normalmente em seu dia-a-dia. Estas pessoas reeducam os sentidos a fim de que os mesmos capacitem-se a perceber estímulos menores. Este processo, na grande maioria das vezes, complexo, se combinado com o que chamamos de negação da condição cego, normal nos primeiros tempos, é prejudicado. A reeducação dos sentidos é um processo doloroso, visto que até então, as experiências dos mesmos tinham também como base o sentido visual.

Um agravante à luta interna é a luta externa que o indivíduo tem que travar em favor da sua subsistência, redefinição do seu papel na sociedade, reabilitação ou habilitação ocupacional. Tereza comenta: "As pessoas teimam, em vez de dizer para a direita, para a esquerda, não tem esta paciência, esta educação de dizerem, só dizem é para cá, é para lá, tu vai saber, um cego vai saber se é a direita ou para esquerda. Assim desde a televisão, olha para mim aprender ligar estas televisão moderna é um sacrifício, prá mim é moderna, porque eu sou cega a 18 anos, então todas estas coisas que não tinha quando eu enxergava para mim é moderno." A não possibilidade ou condição para superar estas lutas pode levar, como no caso de alguns sujeitos desta pesquisa a uma institucionalização, como na fala de Tereza: “ se eu não tivesse cega eu 
não estaria aqui, se eu não tivesse ficado cega eu não teria vindo para cá, e foi por isso que eu parei de dar aula."

A maioria das pessoas que perdem a visão passam por um período de não aceitação e podem chegar a extremos como depressão, isolamento e até vontade de parar de viver, pois como nos diz Anache (1994,p.83) "[ . . . ] a deficiência visual adquirida, é para o seu portador uma experiência de morte.", criam-se então sentimentos de negação ou revolta quanto a condição cego, como na fala de Cecília: "Não faz muito que eu fiquei [cega], mas eu não fiquei [ . . . ] eu enxergo um pouco eu não tô cega, a claridade eu enxergo. Contrapondo-se com: "Que jeito que eu vou ir [na missa] se eu não enxergo."

Fala de Tereza: "Não acostuma, a gente não acostuma $[\ldots$. . eu sou assim sabe, eu sou uma pessoa muito triste de ter ficado cega."

\section{Conclusão}

Após termos conhecido um pouco mais sobre cada colaboradora deste estudo, é hora de pensarmos em tudo o que aprendemos, o que poderemos fazer para melhorarmos a realidade apresentada, para que este trabalho seja válido.

Quando no meio das tardes de fervorosas conversas, nos remetíamos a proposta de trabalho, nos emocionávamos e intrigávamos com o que as idosas contavam de suas vidas, pois, apesar de todas poderem se encaixar num quadro de acontecimentos ou característica, ou seja, serem mulheres, idosas, asiladas na mesma instituição e com cegueira adquirida, cada uma delas possui um modo característico para encarar a própria vida, assim sendo, para algumas a aquisição da cegueira se constitui uma grande perda, a ponto de dizer "Uma pessoa cega minha filha, não é nada.", outras, porém apesar de cegas criaram filhos, trabalharam, continuaram levando a própria vida e com bastante autonomia. Podemos então pensar quais foram os motivos que talvez "forçaram" algumas destas mulheres a não se abalarem tanto com a própria deficiência e a reassumirem suas vidas.

Podemos observar, por exemplo, a vida da Lurdes, que trabalhou muitos anos em um asilo, para ela a institucionalização não foi impactante, continuou trabalhando no Lar, fez muitos amigos, enfim fez com que parecesse que apenas passaria a permanecer à noite em seu 
local de trabalho. Porém quando ficou cega sentiu todas as conseqüências de um internamento asilar, fechou-se em seu mundo particular, como retratado na fala de uma das funcionárias " [ . . . ] agora ela não tem amizades, assim amigos sabe, por que ela nem tenta se comunicar, ela não sabe quem tá do lado, acaba ficando sempre quieta, antes era bem ativa." Contrapondo-se, por exemplo, com a história de Olga, que quando adquiriu a cegueira começou uma nova etapa em sua vida a fim de se readaptar em seu ambiente e restabelecer a própria autonomia.

Nos remeter a textos de Neri (2002) quando nos fala sobre as categorias que tem influência sobre o desenvolvimento, mais especificamente as influências não normativas, caracterizadas por conter eventos de caráter biológico ou ambiental, que não tem caráter universal, nem sua ocorrência é previsível, em matéria de época ou de seqüência para indivíduos ou para grupos, formando então perfis vitais diferenciados, que fazem com que as pessoas sejam diferentes entre si.

Consideraremos o que diz Neri (2002,p.43) para analisarmos por que as pessoas reagem de forma diferenciada ao mesmo evento:

[... ] com o envelhecimento diminui a plasticidade comportamental, definida como a possibilidade de mudar para adaptar-se ao meio (por exemplo através de novas aprendizagens) e diminui a resiliência, definida como a capacidade de reagir e recuperar-se dos efeitos da exposição a eventos estressantes (por exemplo doenças e traumas físicos e psicológicos).

Apenas esta constatação talvez nos traga muitas respostas, como, por exemplo, o porquê Lurdes e Cecília, que ficaram cegas depois dos 60 anos, não construíram quase nenhuma estratégia para enfrentar essa sua nova condição - cega, muito diferente, por exemplo, de Antonia e Olga que adquiriram a cegueira com 20, 30 anos. Além de também explicar por que as duas primeiras não se readaptaram ao meio após terem se tornado cegas como observamos dentro do asilo.

Observamos dentro da instituição as limitações no dia-a-dia das internas, enquanto Cecília, segundo a funcionária, “[ . . . ] não faz praticamente nada sozinha, para ir ao banheiro, para tomar água, para ir até o refeitório, para quase tudo precisa de ajuda [ . . . ]", não tendo, portanto independência nas atividades cotidianas, Antonia apesar da idade é bem 
independente, como expresso na fala da irmã responsável pela ala: “[ . .. ] vai ao banheiro sozinha, se localiza nos corredores com pontos de referência (pia, a sala) se veste sozinha, ajeita a própria roupa."

Diferentemente, no entanto, podemos observar a vida de Tereza que apesar de ter se readaptado, pelo menos em parte no seu cotidiano, ou seja, apresenta uma certa autonomia no deslocamento, nas atividades da vida diária não conseguiu superar a tristeza de ter se tornado cega, como ela mesma relata várias vezes: "eu sou uma pessoa muito triste de ter ficado cega [ . . . ] a gente não se conforma [ . . ] não é fácil, fiquei cega, fiquei longe? da minha gente."

Sendo esta característica nada mais do que um critério subjetivo decorrente de seu curso de vida. Tereza por ter sido uma mulher muito doente pode ter aprendido a esforçar-se fisicamente para superar seus problemas, mas não ter mais condições psicológicas de enfrentá-los.

Unindo estas observações com o que nos diz Santos $(1998$, p.1) que "[ ... ] o deslocamento nos diferentes espaços proporcionará ao indivíduo cego diferentes estímulos de memória e de organização espaço-temporal a fim de propiciar maior interação com a sociedade evitando o seu isolamento." Percebemos que as idosas cegas que apresentam maior autonomia de deslocamento apresentam maior número de pessoas que podem chamar de amigas, como Tereza, Olga e Antonia, contrapondo-se com Cecília e Lurdes que permanecem a maior parte do tempo sentadas no sofá da sala e por isso pouco interagindo com as pessoas mais independentes e sem problemas cognitivos que geralmente ficam pelos corredores ou em outra sala, as duas acabam por se isolar cada vez mais.

Grifa-se que as primeiras podem fazer amizades justamente por pedirem a uma vidente que thes auxilie a chegar ao ambiente desejado. O que se sobressai neste caso não é a autonomia total, mas sim algumas possibilidades de deslocamento unidas ao desejo de locomoção.

Percebemos que quando o indivíduo aceita a condição de cego começa também a aceitar que outros o ajudem em razão da deficiência e consegue então retomar sua vida mais facilmente apesar das dificuldades. Quando há, porém, a negação da cegueira, como é o caso de Cecília: "Eu não to cega, a claridade eu enxergo.", ou a esperança de voltar a enxergar em casos em que não há perspectivas como no caso de Lurdes: "Deus vai me ajudar a voltar a enxergar.", há uma necessidade 
de repelir inconscientemente a ajuda dos outros, e dessa forma acabam se isolando cada vez mais.

Em resumo, quanto mais o aspecto social estiver desenvolvido maior é a possibilidade de autonomia nas atividades de vida diária, como a exemplo de Antonia: "Quando eu cheguei no asilo, dois ou três dias depois que eu tinha chegado, uma velha que era cega também, ela tinha um bastão. Ela me deu o bastão e me disse: "Vai palpando a casa com o bastão para ti conhecer a casa [ . . . ]'." Justifica-se desta forma a importância de conhecer um pouco da história de vida de cada uma destas pessoas para que assim se proporcione maiores trocas entre cuidadores/internos, internos/internos, profissionais/internos, e se possa ter ganhos no aspecto social visando maior autonomia no dia-a-dia e conseqüente adaptação.

\title{
A STUDY ON REFUGEES SENIORS WITH ACQUIRED BLINDNESS
}

\begin{abstract}
This work was developed with the objective to know the refugees seniors of the Asilo Amparo Providência Lar das Vovozinhas, with acquired blindness; your daily autonomy and the strategies of adaptation of the same front the acquisition of such deficiency. The subject of the research are above five internal seniors in the institution referred. As form of collect of dice was accomplished interviews, that can be characterized as of spoken history, where if tried to meet information of the collaborators' life through a route with applied open questions the same ones and, other route with applied open questions to people that now do part of the middle in that the collaborators are inserted, as form of obtaining information on the autonomy of each senior one that is part of the study and after, qualitative analysis was accomplished. They were observed for the study the consequences of the departure for the asylum and of the acquisition of the blindness, as well as an abbreviation report on the report of the institution and your current structure. It was ended that the more the coexistence with other adult be developed greater is the autonomy possibility in the activities of daily life.

Keywords: Third Age. Asylums. Blind.
\end{abstract}




\section{REFERÊNCIAS}

ANACHE, A. Educação e Deficiência: estudo sobre a educação de pessoa com "deficiência" visual. Campo Grande: CECITEC/UFMS, 1994.

CARDOSO, R. S. O Jogo Clownesco e suas Significações no Cotidiano Asilar. Dissertação (Mestrado em Ciência do Movimento Humano)-Universidade Federal de Santa Maria, Santa Maria, 2001.

CORTELLETTI, I. A. ;CASARA, M. B. ; HERÉDIA, V. B. M. Idoso Asilado: um estudo gerontológico. Caxias do Sul, RS: EDUCS, 2004.

DOLL, Johannes. O Campo Interdisciplinar da Gerontologia. In: PY, Ligia et al. (Org). Tempo de Envelhecer: percursos e dimensões psicossociais. Porto Alegre: Nau, 2004. P. 83-107.

GOFFMAN, E. Manicômios, Prisões e Conventos. 5. ed., São Paulo: Perspectiva, 1996.

NERI, A. L. Teorias Psicológicas do Envelhecimento. In: FREITAS, E. V. et al. Tratado de Geriatria e Gerontologia. Rio de Janeiro: Guanabara Koogan, 2002.Cap.04, p.32-45.

SANTOS, A. O Cego, o Espaço, o Corpo e o Movimento: uma questão de orientação e mobilidade. Rio de Janeiro, Revista Benjamim Constant, Ano 5, $\mathrm{n}^{\circ} 11,1998$.

SOCIEDADE BRASILEIRA DE VISÃO SUBNORMAL. Conceito de Visão Subnormal. [2003]. Disponível em: $<$ http://www.cbo.com.br/subnorma/conceito.htm>. Acesso em: 09 set. 2007.

Recebido em: 11.04.2007

$1^{a}$ Revisão: 14.05 .2007

$2^{a}$ Revisão: 19.07.2007

Aceite final: 25.09.2007 